\title{
Research on Innovation and Development of Wuhan East Lake High-Tech Zone's Regional Economy under the Economic New Normal
}

\author{
Yan-Qiu Li \\ School of Management, Wuhan University of Technology, \\ Wuhan, China \\ Email: lyqjobmail@163.com,
}

\begin{abstract}
As the first batch of national high-tech industrial development zone, Wuhan East lake High-tech Development Zone is not only a high-tech industrial clusters, but also the area of Wuhan future important innovation and economic development. Under the background of economic globalization and regional economic integration, the development of regional economic innovation largely determines the development of the regional, even the development of the national, How to utilize the potential relationship between regional innovation and regional economy under today's background of Economic New Normal, which means taking advantage of regional innovation for the growth of economic and the development of regional economic can conversely promote the development of regional innovation, then fully play its role in boosting development in surrounding areas has become a crucial question.
\end{abstract}

Keywords- East Lake High-tech Development Zone; Regional economic; Regional innovation; Economic New Normal

\section{INTRODUCTION}

"New normal" was put forward first by Mohamed El-Erian, the President of the Pacific fund management company, China's new normal is characterized by the economy growth in high-speed slow down to high-middle speed, growth pattern changing from extensive growth to innovation and consumption-driven type[1].Innovation can fundamentally change the pattern of economic development, the ultimate goal is not just about the output of innovation, more is about the driving ability of regional economic development and the capacity of production pattern transformation. Wuhan East Lake high-tech Development Zone is located in Hubei province the hinterland of central, which is the important growth pole of regional economic development, facing the development of west and east, rapid development has become the most important task.

\section{LITERATURE REVIEW}

Regional innovation ability has long been regarded as important driving power for regional economic development, it can effectively promote regional economic growth, industrial structure upgrading and regional competitiveness

\author{
Jun Feng * \\ School of Management, Wuhan University of Technology, \\ Wuhan, China \\ Email:fj6799@sina.com
}

promotion. Accordingly, the development of regional economy can provides the material foundation and environment support to the improvement ability of the regional innovation [2].Therefore, regional innovation capacity and regional economic development are complementary to each other.

Liu Yin (2014) argues that the deeper level of demand of regional economic development come from the institutional change and institutional innovation [3].Tang-wei teng (2013) thought the world first-class high-tech advantage mainly in research and development ability, high level of industry and global netting [4].Lilin (2013) argues that scientific and technological innovation has become an important driving force of regional economic development and social progress [5]. While science and technology innovation is based on the input about science and technology Investment. Zhu Jieting (2013) argues that regional culture directly affects people's thought, idea, value orientation and mental outlook, etc. The development of regional economy determines the development of regional culture. Regional culture is the indispensable precondition and spiritual power for regional economy overall development [6].

\section{THE DOMESTIC AND FOREIGN HIGH-TECH ZONES' REGIONAL ECONOMY INNOVATION AND DEVELOPMENT MODE AND CHARACTERISTICS}

With the growing of global innovation networks, the world's leading high-tech zones have become the core of the global knowledge network. Throughout the development of different domestic and foreign high-tech zones, the successful high-tech zones have similar features, but each is different

\section{A. Foreign High-Tech Zone Development Model and Characteristics}

Silicon valley has experienced a tortuous development process as the first high-tech park in the world since it set up in 1951 named Stanford industrial park. Along with the deepening development of economic globalization, the valley gradually broke the ego driven pattern development and became a new model focusing on global interaction. Establishing a good cooperation relationship among the firms, universities and research institutes is a geographic advantage model which advocated by the father of "silicon valley" prof Terman, as well as the initial model the rest of the world copied. Silicon valley adhere to promote 
cooperation among the three of universities, research institutions and enterprises, which have been proved to be a necessary way to exploit high technology and high-tech industries. People in here have high loyalty of industry and technology makes it easier for them to sharing their experience, knowledge and technology, all of this greatly enriched the openness of the silicon valley culture, and improve the creativity of the entire industry. Silicon valley 'success cannot be separated from the large number of venture capital. Venture capital help small or medium-sized of science and technology enterprise to solve the financial matter at the beginning, so far, it has supported a lot of high-tech companies such as Intel, amazon, apple and so on. Venture capital is, so to say, Silicon valley's financial engine.

Daedeok Innopolis which known as the "silicon valley in Asia", has a reputation first-class universities and research institutions in the world, large quantities of outstanding researchers, advanced research equipment, major technical innovation and industrialization and innovative entrepreneurship environment, etc.

Tsukuba scientific city is located in the center of Tsukuba, it is a well-equipped, complete structure and numerous scientific research personnel. Tsukuba science city has formed a unique situation in the process of development, mainly includes: national unified leadership, collaboration, unified coordination, which largely improve the efficiency of development ;it also have a sound legal system and varieties of preferential policies to protect and promote the comprehensive development of Tsukuba city; Tsukuba city combined their own advantages with the environment of research and development, then adjusted measures to local conditions and eventually achieved a huge success.

\section{B. Domestic High-Tech Zone Development Mode and Features}

Zhongguancun national innovation demonstration area has become the most innovative, scientific and technological personnel gathering area since 1980.it has a group of universities like, Tsinghua university, peking university and others, and the group of scientific research institutes represented by the Chinese Academy of Engineering and Chinese Academy of Sciences, it also has a large number of national key laboratories, national engineering research center, national technology research center, as for enterprise, it produced a batch of national outstanding brand such as Lenovo, Founder, Tsinghua tongfang. Compared with other high-tech zone, zhongguancun's development characteristics mainly embodied in the following aspects: adopting the combination mode of market orientation and government support; using creative universities and scientific research institutions as the force to provide Zhongguancun with the technical support and personnel support, attracting many foreign outstanding enterprises, for example, Ericsson, MOTOROLA, SONY and so on to gradually realize the internationalization development; adopting "trade for technology", "trade for workers", metallurgical development model to obtain fund to learn about the world of high-end dynamic development in time.
Shanghai zhangjiang High-tech Industrial Development Zone was founded in 1992, after 20 years of rapid development it has become a demonstration base about the technological innovation and the transformation and industrialization of scientific and technological achievements, and gradually formed the unique "zhangjiang model", it has already become main force to promote scientific and technological innovation and industry transformation in Shanghai. Zhangjiang innovation demonstration area of the main features: making the best use of the circumstances to actively promote the essence of deepening development of leading industry; By establishing Zhangjiang innovation institute to expand the financing channels, establishing venture center and a series strategies to provide enterprises with innovative service and good environment for high-tech development; By deepening the reform of system and mechanism and optimizing the environment of innovation and strategic positioning to digging their own potential and pursuit of new constant development.

Taiwan Hsinchu science park was founded in 1976 by the Taiwan authorities to imitate the Silicon Valley in United States。this is the main characteristic of Hsinchu science park supplying scientific plan and management service for the park by developing science and technology park in the future vision plan; The various preferential policies greatly mobilized the innovation of the enterprise vitality such as preferential tax policy, capital allowances , policy of land and plant rental, the establishment of technology innovation policy, and so on . They also try to take measures to attract overseas talents, set up a technology development award, attache great importance to the local talent cultivation and cooperate with universities and scientific research units and other reasonable talent introduction and training policies, all of this have made a significant contribution to the development of Hsinchu science park.

The rapid development of the high-tech zone is no longer simply due to the internal network of effective connection and the commercialization capability of local knowledge , knowledge networks and clusters of outside areas are important for the development of high and new zone especially for the development of small and medium-sized enterprises cluster in the zone, there are more and more knowledge and innovation comes from the global knowledge network [7]. Thus, strong scientific base, entrepreneurial culture, ability to attract talent, financial support, public policy, strong intellectual property protection and governance and global network links a series of key elements are the common characteristics of the world's leading high-tech zone which determine the success of high-tech zone future development.

\section{EAST LAKE HIGH-TECH ZONE INNOVATION REGIONAL ECONOMIC DEVELOPMENT SITUATION}

Wuhan East Lake High-tech Zone construction started in 1988, was formally approved as the national high-tech industrial development zone by the state council in 1991.In 2001, it was approved by the state planning commission, ministry of science and technology for national as the 
optoelectronic industry base, namely, "wuhan China optical valley". From the fig.1 you can see, East Lake high-tech zone's total revenue has grown steadily since 2009, the growth rate has been around $30 \%$, the total revenue reached 852.6 billion yuan in 2014. Although the East Lake High-tech zone has obtained certain achievements in innovation entrepreneurship environment, innovation ability and high technology industries since its started, but compared with the world first-class high-tech zone such as the Silicon Valley in United States, zhongguancun in Beijing, it still exists certain gaps.

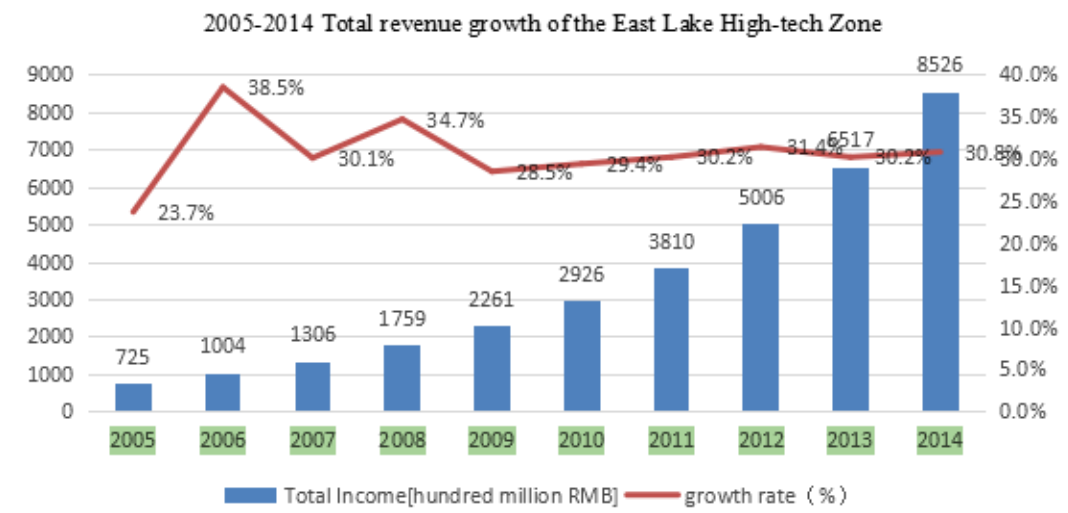

Figure.1. Total revenue growth of the East Lake High during 2005-2014(Data sources:2014 Annual Report on Innovation and Development in Wuhan East Lake High-tech Development Zone)

International high-end innovation resources agglomeration situation preliminary revealed, but the structure of senior professionals become unbalance. Numerous East Lake High-tech zone has a lot of colleges and universities, there are also many research institutions and scientific research personnel, the East Lake High-tech zone is China's second largest concentration areas of intelligence. However ,Specialized talented staff who are familiar with international business like international professional consulting firm, a high level of accountants, lawyers, agent technology, returned overseas entrepreneurship are less, so with the introduction of talent resources related to personnel, the information collection of senior talent, key business project tracking and supporting policy remain to be strengthened.

The innovation of science and technology constantly emerging, but the main body role of science and technology innovation has not been given full to play. After years of development the East lake high-tech zone has got lots of scientific and technological achievements and science and technology innovation strength is growing. But overall, the enterprise's R\&D investment is still in a lower level。East Lake High-tech zone's in 2014 total revenue was825.6 billion yuan, but the R\&D expense only 20.73 billion yuan, $2.4 \%$ of total revenue; the R\&D input intensity is less than the international average of $5 \%$, and has a tendency to decline. R\&D and revenue ratio is shown in the table below, it can be seen during 2010-2010 even the East Lake High-tech zone's R\&D input was gradually increasing, but less than $5 \%$, and the trend of annual ratio is lower. The patent application and patent authorization as shown in the picture below: patent application and patent grant are gradually increased, but overall, the increase in patent application quantity increased faster than authorization quantity.

TABLE.I 2010-2014 THE TOTAL INCOME AND R\&D

\begin{tabular}{c|c|c|c}
\hline year & R\&D & Total income & R\&D/TI \\
\hline 2010 & 78.7 & 2926 & 0.027 \\
\hline 2011 & 105.3 & 3810 & 0.028 \\
\hline 2012 & 149.9 & 5006 & 0.030 \\
\hline 2013 & 168.7 & 6517 & 0.026 \\
\hline 2014 & 207.3 & 8526 & 0.024 \\
\hline
\end{tabular}




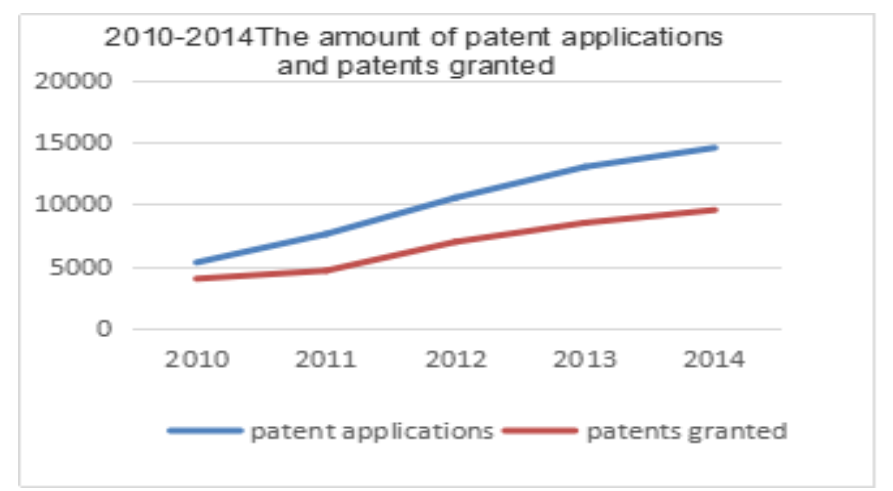

Figure.2. 2010-2014The amount of patent applications and patents granted(Data sources:2014 Annual Report on Innovation and Development in Wuhan East Lake High-tech Development Zone)

The level of internationalization is low, Science and technology leading enterprises is less, and the international competitiveness is not strong. East Lake High-tech zone lack of some of internationally influential enterprises and scientific research institutions, etc. Such as zhangjiang national independent innovation demonstration area has gathered a large number of domestic and foreign well-known software companies and research institutes, including BaoSight, United States citigroup, INFOSYS, TATA ect. Eight in the top 30and 11 in China's top 100 have set up R\&D center in zhangjiang, so compared to the zhangjiang, East Lake High-tech zone lacks scientific research centers and institutions with international influence.

East Lake High-tech zone's industry specialization degree is low, Now there are many enterprises in the hi-tech zone, But specialization cooperation between each other is not close and horizontal complementary is relatively inadequate , the driven interactions between enterprises is not obvious either. Besides its intermediary institutions and science and technology financial service system are not perfect. now, The number of financial institution whose headquartered in wuhan are less than 20, 78 in shenzhen, Beijing zhongguancun gathered 2300 various financial fireworks .Thus, East Lake High-tech zone's science and technology financial services is very limited, and the driven force of regional economy is limited too.

Although during the past few years the East Lake High-tech zone has established lots of policy and has a strong scientific and technological innovation entrepreneurship culture atmosphere, the culture soft power in this city is weak. At present, Wuhan East Lake High-tech zone has introduced a series of policies and measures from the national level and local provinces and cities, and park level to support the innovation development of the enterprise. But from the point of the whole city, the real city spirit and culture has not yet formed, East Lake High-tech zone's international company is less, the ability of international culture diffusing, communication and absorption are limited, these are to some extent restricted the development of east lake high-tech zone.

\section{EAST LAKE HIGH-TECH ZONE INNOVATION REGIONAL ECONOMIC DEVELOPMENT STRATEGIES}

East Lake High-tech Zone should face up to their own development gaps and weaknesses, take advantage of existing strengths and opportunities, and learn from the successful experience of domestic and international top-level innovation demonstration area to promote their development.

Promoting the construction of regional economy innovation network to take obvious regional advantages of economic innovation competitiveness. East Lake High-tech zone should promote mutual cooperation among the government, business, universities, research institutes, financial institutions and intermediary services this six subjects. Construct the integrated technology innovation system which dominated by different kinds of innovation subjects like government, business, universities, research institutes so on. East Lake High-tech should support enterprises to accelerate the pace of innovation and development, and promote the development of high-tech industry chain group. Accelerate the construction of economic innovation platform, with the regional innovation and development of new environment encourage enterprises to expand and give full play to the guiding role of government in improving the industrial innovation platform, public information service platform and accelerate scientific and technological achievements.

Promoting the international development of the East Lake High-tech Zone. Actively seek opportunities for cooperation with multinational tech Zone to promote research and gather factor mobility, international cultural exchange activities to encourage all kinds of education and high-tech area of the international education standards and the establishment of a sound mechanism to facilitate overseas talent to attract international talents meanwhile to strengthen international train the local talents. In financial services technology, East Lake High-tech zone should accelerate the establishment of scientific and technological innovation service about financial and investment system to fit with the international 
norms. In the business construction aspect, it should actively attract foreign medium-sized enterprises to enter the high-tech zone to establish regional companies and research centers to promote technical cooperation projects between enterprises. At the same time, High-tech Zone ought to attract international $\mathrm{R} \& \mathrm{D}$ investment and encourage enterprises to develop high-tech zones overseas technology mergers and acquisitions to strengthen international scientific and technological cooperation.

The enhancement of the degree of specialization of industrial high-tech area. Through the cooperation with domestic and international businesses to strengthen the interaction effect between enterprises to achieve the win-win situation. In the patent application, Although the patent is the companies competition for strategic resources, the expenditure for the maintenance and management is huge, if it cannot be converted effectively into corporate earnings it will be helpless for the improvement of the enterprise's comprehensive strength. Thus, within a certain range, companies should maintain a reasonable number of patents and improve patent quality. In addition, strengthening the agency and financial service system construction, learning the advanced experience from Silicon Valley, as well as Beijing Zhongguancun, Shanghai Zhangjiang and other areas to improve Wuhan service platform high-tech zones and encourage financial market product innovation and enhance innovation service capabilities of intermediaries and financial institutions .

The soft environment construction for the regional economy and innovation development need to attract much more preferable factors to input. it refers to the sum of something outside material conditions, such as policies ,cultural, institutional, legal, ideas and other external factors and conditions.

Regional economic innovation and development is inseparable from cultural construction, it is the important safeguard to encourage market subjects, the spirit of innovation encourage success but also tolerate failure. East Lake High-tech Zone should actively introduce high-quality educational resources, especially international quality education resources to carry out international cooperation in running schools and develop the international cultural market. Owing to the regional culture of tolerance, Silicon Valley has become the world-class high-tech industry gathering innovation and entrepreneurship. Wuhan East Lake High-tech Zone should fully combine their basis of cultural identity to construct regional culture of innovation and development.

What's more government support is necessary for the optimization of regional innovation and economic development of the soft environment. The government should give full play to the function-oriented of the fiscal policy funds with making use of government investment to attract outside capital to expand the scale of investment. Meanwhile, providing some innovative companies with some modest tax breaks, financing policy and so on to reduce the pressure on enterprises survive and attract some of high-tech enterprises to rich regional ecological development and support the sustainable development of High-tech Zone.

\section{CONCLUSION}

Accelerate economic development under the New Economic Normal of Midwest China, innovation and economic development in the region is growing, which will not only become the new norm of the regional economic development, but also will become the future-oriented to the economic policies and reforms. Based on the study and summary of other top-level high-tech zone in both domestic and overseas and their own advantages, this paper identified the problems and deficiencies about the tech Zone in all aspects and proposed future development measures and area economic innovation and development of new model, it should actively create the soft environment for innovation and development of the regional economy and enhance international development and professional level; with high level of regional innovation to promote regional economic development, and in turn to enhance the capacity of regional innovation, then build East Lake High-tech Zone a new international model for innovative development of regional economy.

\section{ACKNOWLEDGEMENT}

This paper is supported by" China Scholarship Council", the Fundamental Research Funds for the Central Universities (2011-1b-009).

\section{REFERENCES}

[1] Information on http://www.pangod.com/news/others/2015/0126/1889.html

[2] Hui Wang. Research on Relationship between Regional Innovation and Economic Development of Zhejiang University of Technology, 2012.

[3] Yin Liu. Coordinated development of Chinese Regional Economic Research System. Jilin University, 2014.

[4] Tangwei Teng. Reaseach on National High-tech Zone in transition new path-a world-class science park perspective Science and Technology Progress and Policy, 2013, 30 (5): 31-36.

[5] Lin Li. The Empirical and Mechanism Study on the relationship among the science and technology investment, innovation and economic. Jilin University, 2013.

[6] Jieting Zhu Research on regional culture effect on Regional Economic Development. Kunming University of Technology, 2013. 